\title{
Evaluation of modeled surface ozone biases as a function of cloud cover fraction
}

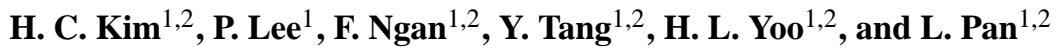 \\ ${ }^{1}$ NOAA Air Resources Laboratory (ARL), NOAA center for Weather and Climate Prediction, \\ 5830 University Research Court, College Park, MD 20740, USA \\ ${ }^{2}$ Cooperative Institute for Climate and Satellites, University of Maryland, College Park, MD 20740, USA \\ Correspondence to: H. C. Kim (hyun.kim@noaa.gov)
}

Received: 4 March 2015 - Published in Geosci. Model Dev. Discuss.: 14 April 2015

Revised: 17 August 2015 - Accepted: 25 August 2015 - Published: 25 September 2015

\begin{abstract}
A regional air-quality forecast system's model of surface ozone variability based on cloud coverage is evaluated using satellite-observed cloud fraction (CF) information and a surface air-quality monitoring system. We compared $\mathrm{CF}$ and daily maximum ozone from the National Oceanic and Atmospheric Administration's National Air Quality Forecast Capability (NOAA NAQFC) with CFs from the Moderate Resolution Imaging Spectroradiometer (MODIS) and the US Environmental Protection Agency's AirNow surface ozone measurements during May to October 2014. We found that observed surface ozone shows a negative correlation with the MODIS CFs, showing around $1 \mathrm{ppb}$ decrease for $10 \%$ MODIS CF change over the contiguous United States, while the correlation of modeled surface ozone with the model CFs is much weaker, showing only $-0.5 \mathrm{ppb}$ per $10 \%$ NAQFC CF change. Further, daytime CF differences between MODIS and NAQFC are correlated with modeled surface-ozone biases between AirNow and NAQFC, showing $-1.05 \mathrm{ppb}$ per $10 \% \mathrm{CF}$ change, implying that spatial and temporal misplacement of the modeled cloud field might have biased modeled surface ozone level. Current NAQFC cloud fields seem to have fewer CFs compared to MODIS cloud fields (mean NAQFC $\mathrm{CF}=0.38$ and mean MODIS $\mathrm{CF}=0.55$ ), contributing up to $35 \%$ of surface-ozone bias in the current NAQFC system.
\end{abstract}

\section{Introduction}

Ground-level ozone is a secondary pollutant resulting from photochemical reactions between oxides of nitrogen $\left(\mathrm{NO}_{x}\right)$ and volatile organic compounds (VOCs) in the presence of solar radiation. While local ozone production is affected by numerous factors, including precursor emissions and meteorological conditions such as temperature and local circulation, ozone photochemistry is photon-limited, and net ozone production shows a direct relationship with changes in UV actinic flux resulting from clouds and aerosols (Dickerson et al., 1997; He and Carmichael, 1999; Jacobson, 1998; Monks et al., 2004). For instance, Lefer et al. (2003) showed that without sufficient UV radiation, ozone production in Houston is limited regardless of local circulation patterns or emission sources. Studies in the urban cities of Los Angeles, California (Jacobson, 1998), and Mexico City (Castro et al., 2001; Raga et al., 2001) also showed that surface ozone varies from 5 to $30 \%$ due to light-absorbing aerosols. Model studies have shown that surface ozone is affected by cloud fields (Voulgarakis et al., 2009; Wild et al., 2000) or strongly scattering aerosols (Dickerson et al., 1997; He and Carmichael, 1999).

Since clouds play a critical role in the radiative balance of the Earth, their impact and models' capabilities to simulate clouds have been repeatedly tested from global and climate perspectives (Bergman and Salby, 1996; Eastman and Warren, 2013; Stephens, 2005). Clouds also play an important role in regional air quality, impacting both surface ozone and particulate matter by regulating photochemical reaction rates, heterogeneous chemistry, and the evolution and partitioning of particulate matter. These impacts, however, still 
have high measurement uncertainties and are not well quantified. While reliable estimates of photolysis rates are essential for reducing the uncertainty in air-quality modeling, most current models use highly parameterized methods to estimate photolysis rates. Pour-Biazar et al. (2007) argued that the uncertainties in estimation of cloud transmissivity and errors in the placement of clouds' location and time could be an important source of uncertainties in simulations of surface ozone, demonstrating during the Texas Air Quality Study campaign that surface-ozone modeling can be improved by adjusting photolysis rates based on the Geostationary Operational Environmental Satellite cloud product. They also stated that the cloud-prediction problem is particularly frustrating when modeling air quality in State Implementation Plans if they are not able to reproduce satellite-observed cloud fields in a model.

In order to reduce computational cost, most regional airquality models, including the US Environmental Protection Agency (EPA) Community Multi-scale Air Quality model (CMAQ), use a two-step approach for calculating photolysis rates (Byun and Schere, 2006). In preprocessing, the clear-sky photolysis rates for a range of latitudes, altitudes, and solar zenith angles are first computed using a radiative transfer module (Madronich, 1987). Then, within the chemical-transport model, the tabular photolysis rates are interpolated for each location and then adjusted using fractional cloud-coverage information. Since most early meteorological models did not generate the full suite of specific cloud and moisture fields required as input for the chemical-transport model, regional air-quality models were designed to diagnose some additional cloud-related fields from meteorological state variables for use in the chemicaltransport model. The Meteorology-Chemistry Interface Processor (MCIP), CMAQ's preprocessor, diagnoses for each horizontal grid cell the cloud coverage, cloud base and top, and the average liquid water content in the cloud using a series of simple algorithms based on a relative-humidity threshold (Otte and Pleim, 2010). For example, in CMAQ modules the photolysis rates below clouds are calculated as

$$
J_{\text {below }}=J_{\text {clear }}\left[1+f_{\mathrm{c}}\left(1.6 \times \operatorname{tr}_{\mathrm{c}} \cos (\theta)-1\right)\right] \text {, }
$$

where $\operatorname{tr}_{\mathrm{c}}$ is cloud transmissivity, $f_{\mathrm{c}}$ is the cloud fraction for a grid cell, and $\theta$ is the solar zenith angle. Cloud fraction is estimated using relative humidity $(\mathrm{RH})$ and critical RH (Byun and Ching, 1999). Cloud fraction $\left(f_{\mathrm{c}}^{k}\right)$ above the boundary layer is

$f_{\mathrm{c}}^{k}=\left[\frac{\mathrm{RH}^{k}-\mathrm{RH}_{\mathrm{c}}}{1-\mathrm{RH}_{\mathrm{c}}}\right]^{2}$,

where $\mathrm{RH}^{k}$ is the relative humidity at vertical model layer $k$ and $\mathrm{RH}_{\mathrm{c}}$ is the critical relative humidity defined as $R H_{\mathrm{c}}=1-2 \sigma_{\mathrm{c}}\left(1-\sigma_{\mathrm{c}}\right)\left[1+1.732\left(\sigma_{\mathrm{c}}-0.5\right)\right]$ and $\sigma_{\mathrm{c}}=$ $p^{k} / p^{k \mathrm{PBL}}$ (Geleyn et al., 1982).
Within the convective boundary layer when $\mathrm{RH}>\mathrm{RH}_{\mathrm{c}}$,

$f_{\mathrm{c}}^{k}=0.34 \frac{\mathrm{RH}^{k}-\mathrm{RH}_{\mathrm{c}}}{1-\mathrm{RH}_{\mathrm{c}}}$

(Schumann, 1989; Wyngaard and Brost, 1984). See line 131177 of bcldprc_ak.f90 for MCIP v3.6.

Although fractional cloud coverage (i.e., cloud fraction) thus plays a crucial role in determining the final values for photolysis rate, it is not a well-defined physical state variable and is mostly threshold-specific for each retrieval algorithm. One may notice that there are two possible uncertainties in modeling cloud fraction: (1) the model's capability to generate the proper amount of cloud fields, both in their displacement and timing; and (2) conceptual consistency in definitions of cloud fraction between model and observation (i.e., from satellite). In this study, we present efforts to evaluate the cloud-coverage information used in a regional air-quality model through satellite-based cloud fraction information and surface-monitored ozone observations. In the second section, we introduce the observational and modeling data used in this analysis, and results are discussed in Sect. 3. General performance of the contiguous United States (CONUS)scale air-quality forecast system and possible overestimation of surface-ozone levels due to uncertainty in cloud fractions will be also discussed.

\section{Data and method}

\section{MODIS}

The Moderate Resolution Imaging Spectroradiometer (MODIS) cloud level 2 product (MOD06_L2 and MYD06_L2, http://modis-atmos.gsfc.nasa.gov/MOD06_ L2/index.html) is used for daily cloud-coverage information for each surface-monitoring site. We have retrieved $5 \mathrm{~km}$ cloud fraction data, which is based on MOD35_L2 cloud-mask information with $1 \mathrm{~km}$ and $250 \mathrm{~m}$ (nadir) spatial resolution. Brightness temperatures (BTs) from multiple channels and their differences (BTDs) are used in cloudmasking algorithms, as described in the MODIS cloud-mask product (MOD35_L2) user guide (http://modis-atmos. gsfc.nasa.gov/_docs/CMUSERSGUIDE.pdf). For example, daytime land-cloud maskings are determined using BTs and BTDs from 1.38, 3.7, 3.9, 6.7, 8, 11, 12, and $13.9 \mu \mathrm{m}$ channels. Only data from local afternoon time $(\sim 13: 30)$, when ground-level data show high ozone-production efficiency, are used in the analysis.

\section{AirNow}

Real-time ozone measurements across the CONUS are provided by the EPA through the AirNow network (http://www. epa.gov/airnow). From more than 1000 Air Quality System (AQS) sites throughout the CONUS, hourly surface ozone 

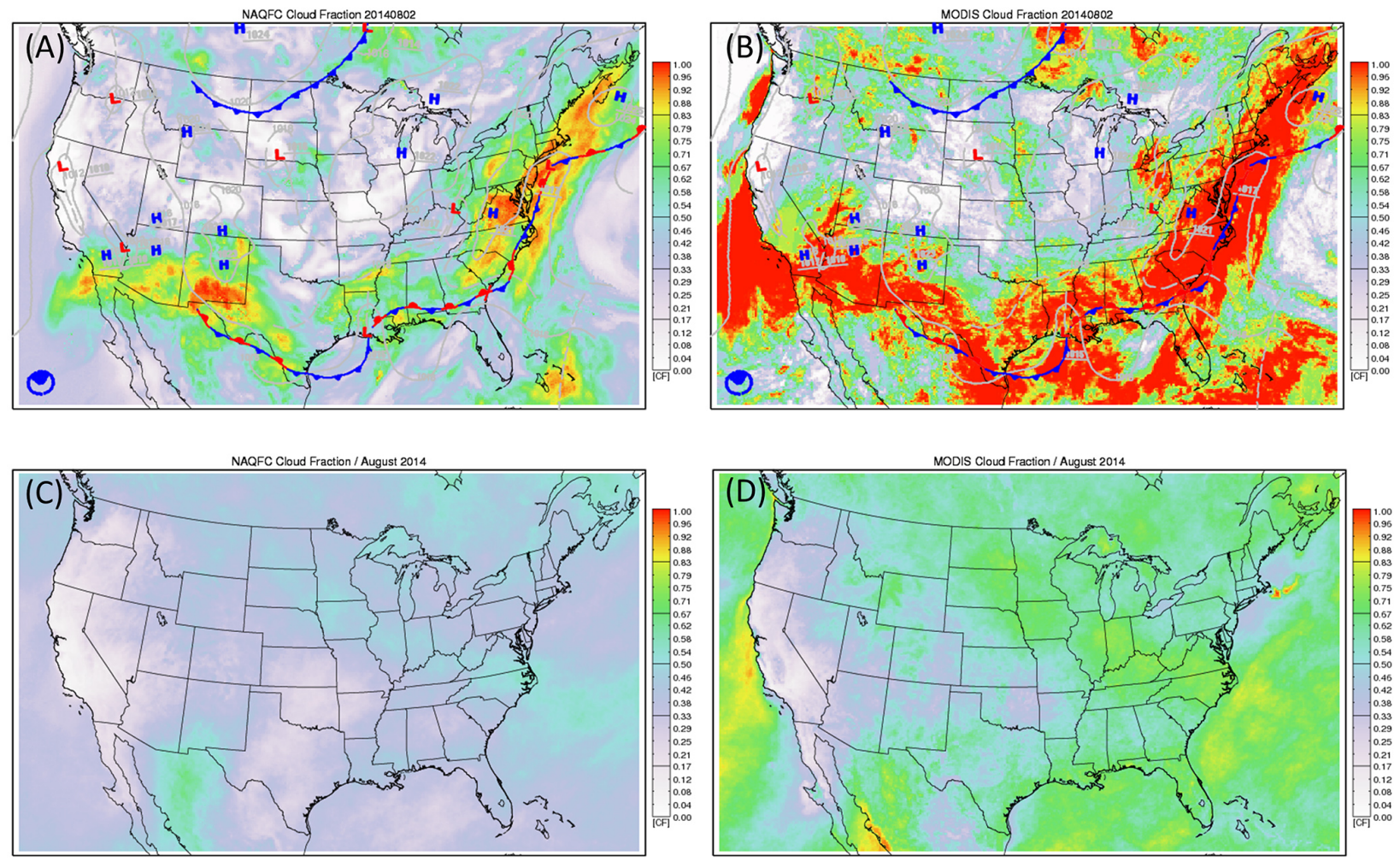

Figure 1. Spatial distributions of cloud fractions on 2 August 2014 from NAQFC (a) and MODIS (b). NOAA NCEP surface weather chart at 18:00 UTC is overlaid. Monthly averaged distributions are also shown for NAQFC (c) and MODIS (d).

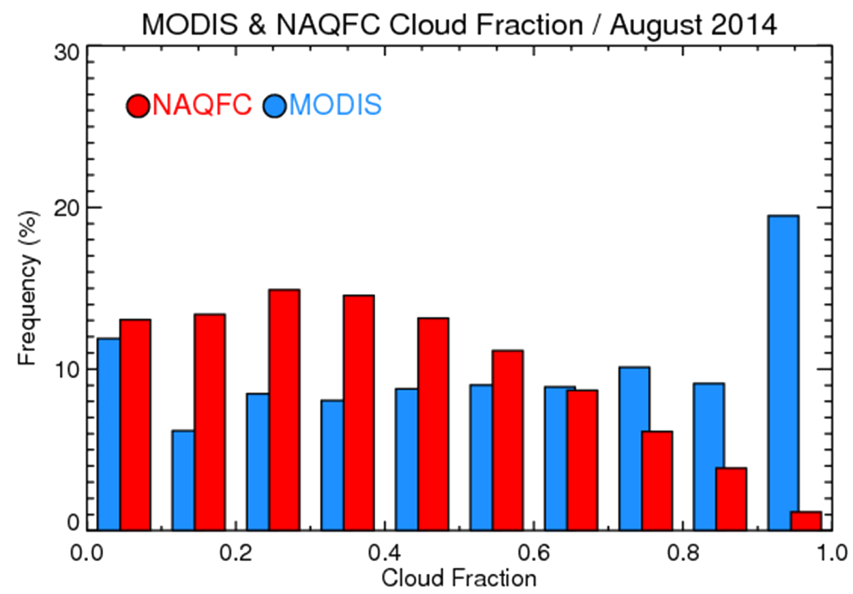

Figure 2. Occurrence frequency histogram for NAQFC cloud fractions (red) and MODIS cloud fractions (blue).

data are obtained, and a daily maximum $8 \mathrm{~h}$ moving averaged ozone (MDA8 ozone) value is calculated for each site.

\section{NAQFC}

The US National Air Quality Forecast Capability (NAQFC) provides daily, ground-level ozone predictions using the Weather Forecasting and Research non-hydrostatic mesoscale model (WRF-NMM) and CMAQ framework across the CONUS with $12 \mathrm{~km}$ resolution domain (Chai et al., 2013; Eder et al., 2009). In our analysis, we used the experimental version of NAQFC, which uses WRF-NMM with $\mathrm{B}$-grid (NMMB) as a meteorological driver and the CB05 chemical mechanism. Meteorological data are processed using the PREMAQ, which is a special version of MCIP designed for the NAQFC system. While NAQFC has shown a tendency to overpredict MDA8 ozone (Chai et al., 2013), recent updates to model processes and emission have reduced its bias. The "CFRAC" variable from METCRO2D output files are used for cloud fraction.

\section{Method}

For each EPA monitoring site and the corresponding model cells, we have calculated a daily maximum of $8 \mathrm{~h}$, forwardmoving, averaged concentrations. For the same locations, we also calculated daytime ( $\sim$ 13:30 local time) cloud fractions from the model and from satellite data. MODIS cloud fractions are regridded into $12 \mathrm{~km}$ domain grid cells using a conservative regridding method (Kim et al., 2013). For consistent comparisons, only valid observational data are used, those with corresponding times and locations. We 

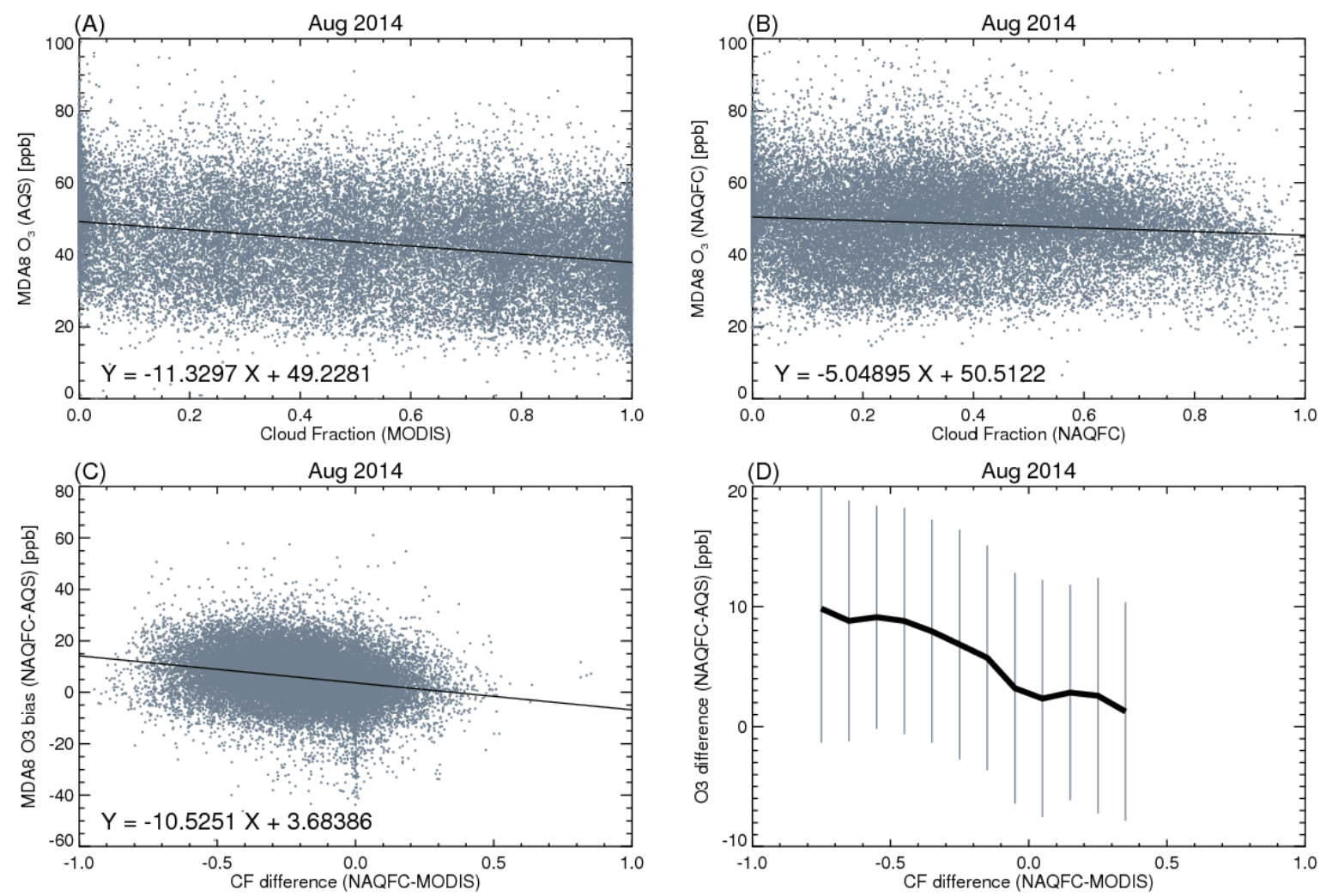

Figure 3. Scattered plots between MODIS cloud fractions and AQS MDA8 ozone (a), between NAQFC cloud fractions and MDA8 ozone (b), and between cloud fraction differences (NAQFC - MODIS) and MDA8 surface ozone bias (NAQFC-AQS) (c) during August 2014 across 1024 AQS monitoring site locations. Averaged $\mathrm{O}_{3}$ biases for each 0.1 cloud-fraction bin with 1 standard deviation (vertical bars) are also shown (d).

have investigated the 6-month summer ozone season (MayOctober 2014) and results are consistent for each month.

\section{Results and discussion}

General distributions of daily and monthly daytime cloud fractions from the model and from satellite are compared. Figure 1 shows the distribution of cloud fractions retrieved from NAQFC and MODIS cloud products (MOD06 level2) for one day (2 August 2014) in the upper panels; and the figure shows a 1-month average (August 2014) in the lower panels. The 2 August plot is overlaid with a NCEP surfaceanalysis chart to show its association with general features of the synoptic weather pattern. It is obvious that both model and satellite correctly display the general features of cloud coverage associated with the synoptic frontal activities. However, there is a serious discrepancy in their quantity; in most cases the amount of cloud fraction used in the model is smaller than the cloud fraction retrieved from the MODIS cloud product. For August 2014, monthly means of daytime cloud fractions from NAQFC and MODIS are 0.38 and 0.55 , respectively.
This discrepancy becomes even more evident from the histogram distribution. In Fig. 2, we present histogram distributions of cloud fractions from NAQFC and from MODIS during August 2014 for each 0.1 cloud-fraction bin. Occurrence frequency is shown on the $y$ axis, so the sum of total frequency makes $100 \%$. In the NAQFC model, lower cloudfraction numbers are more dominant, with the highest frequency between 0.2 and 0.3 , showing very low frequency of high cloud fractions. On the other hand, the MODIS cloud fraction is quite different, showing more of a bimodal distribution. Frequencies for clear sky are similar between the model and satellite, around $12-13 \%$, but the satellite cloud frequency is much lower in the $0.1-0.5$ range and higher above 0.6 .

The reason for this discrepancy between the model and MODIS is not clear and requires future investigation. As mentioned previously, this might be a characteristic of the meteorological model or it could be a conceptual difference in cloud fraction between model and satellite. As cloudfraction field is a diagnosed variable in PREMAQ, which uses a certain threshold of liquid-water content or relative humidity to model the existence of clouds, it may differ from the satellite's measurements of cloud, which uses emissivity- 

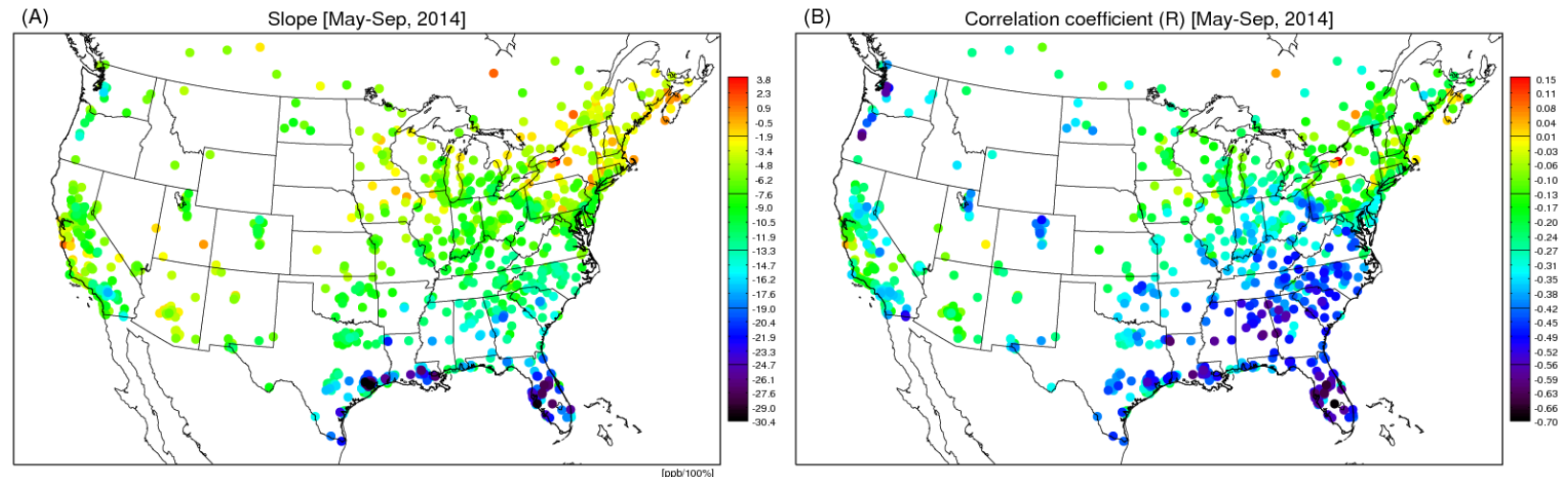

Figure 4. Spatial distributions of (a) slope and (b) correlation coefficient of linear regression between MODIS CF and MDA8 ozone.

based cloud masking using BT and BTD from multiple channels.

Figure $3 \mathrm{a}$ and $\mathrm{b}$ show scatter plots between MODIS cloud fractions and AirNow MDA8 ozone and between NAQFC cloud fractions and MDA8 ozone, respectively, during August 1024 across all reporting EPA AQS monitoring sites. As the amount of UVA (ultraviolet radiation in 315-399 nm) strongly affects the ozone production by $\mathrm{NO}_{2}$ photodissociation (e.g., $j\left(\mathrm{NO}_{2}\right)$ in $\lambda<420 \mathrm{~nm}$ ) at the surface, it is evident that cloud fraction, and the eventual flux of photons reaching the level of the surface, is a very dominant component determining ground-level ozone concentration (Monks et al., 2004; Seinfeld and Pandis, 2006). Scatter plots in Fig. 3a draw data from more than 1000 sites across the CONUS under a variety of meteorological conditions and precursor sources. Even with the high uncertainties here, we can see a notable separation of ground-level ozone for each cloud-fraction bin, implying that photon flux is one of the most dominant features determining tropospheric ozone photochemistry. Slope and offsets for line-fitting MODIS cloud fraction (CF) versus AirNow MDA8 ozone are -11.33 and 49 , respectively, implying that $10 \%$ of $\mathrm{CF}$ change can cause around $1.13 \mathrm{ppb}$ decrease in surface ozone. On the other hand, the correlation between NAQFC CF and MDA8 ozone is slightly weaker (Fig. 3b); slope and offsets between NAQFC CF and MDA 8 ozone are -5.0 and 50.5, respectively, showing half as much sensitivity in surface ozone according to the NAQFC CF compared to the MODIS CF.

Figure $3 \mathrm{c}$ and $\mathrm{d}$ are scatter plots for $\mathrm{CF}$ differences (NAQFC-MODIS) and MDA8 surface ozone bias (NAQFCAQS; left), and averaged $\mathrm{O}_{3}$ biases for each 0.1 cloudfraction bin (right). Since the definition of cloud fraction in the model and the satellite are slightly different, we choose the term "cloud fraction difference" instead of "cloud fraction bias". Slope of the linear regression is $-10.5 \mathrm{ppb} / 100 \%$ $\mathrm{CF}$. The right-side panel shows averages of ozone biases for each 0.1 bin. The vertical bars indicate 1 standard deviation. It is clear that where the model underestimates cloud frac- tion, it likely overestimates surface ozone, although there are many intricacies of tropospheric ozone chemistry involved.

Since Fig. 3 shows data from all AQS sites, it includes multiple uncertainties from each site's local characteristics, such as local emissions. We have conducted further investigation for individual AQS sites to confirm if we can find similar MDA8 ozone to CF correlation. Figure 4 shows spatial distributions of each site's ozone to CF sensitivity (e.g., regression slope of MDA8 ozone and CF) and correlation coefficients during 5 months (May to September, 2014). MDA8 ozone decreases rapidly by the increase of CF in the southern regions, especially near the coastal lines of Gulf of Mexico, such as Texas, Louisiana and Florida, up to $-30 \mathrm{ppb} \mathrm{CF}^{-1}$. In the middle latitude regression slopes are around $-10 \mathrm{ppbCF}^{-1}$, and some northern location areas show positive correlation. Mean of total regression slope is $-8.5 \mathrm{ppb} \mathrm{CF}^{-1}$. Correlation coefficients $(R)$ also show stronger (negative) correlation in southern states, especially southeastern United States up to $R=-0.7$ while northeastern United States shows much weaker correlation, implying accurate CF information is important in southern US states.

\section{Ozone overprediction}

As already described, current NAQFC cloud fields seem to have fewer clouds than MODIS by 0.2 . We have further estimated how this difference can affect the general performance of surface ozone forecast. Previous studies address $\mathrm{O}_{3}$ overpredictions of global and regional chemical-transport models during the summer daytime over the eastern United States (Chai et al., 2013; Eder et al., 2009; Fiore et al., 2009; Murazaki and Hess, 2006; Nolte et al., 2008; Rasmussen et al., 2012; Reidmiller et al., 2009). Studies have addressed that the vertical resolution (Murazaki and Hess, 2006), the coarse representation of emissions (Liang and Jacobson, 2000), along with uncertainty in the heterogeneous reactions of aerosols (Martin et al., 2003) contribute to the highly biased $\mathrm{O}_{3}$ of the global chemical-transport models MOZART or GEOS-Chem over the eastern United States. 
NAQFC also has a tendency to overestimate surface ozone during ozone season. We may estimate the amount of possible overestimation of surface ozone due to the underestimation of the cloud fraction and eventual overestimation of photolysis rate. As the mean cloud fraction of model is 0.17 higher than the cloud fraction estimated from MODIS, by applying the $-10.5 \mathrm{ppbCF}^{-1}$ estimate, we can deduce that $1.8 \mathrm{ppb}$ of the surface-ozone overestimation is contributed from the underestimation of the cloud fraction. Considering current NAQFC surface-ozone overestimation is around $5 \mathrm{ppb}$ for the month of August 2014, we can roughly suggest that almost $35 \%$ of this overestimation is due to faulty estimation of the cloud field. Though this estimate is still very rough, this is definitely something to consider carefully in order to improve the simulation of regional air quality and especially the simulation of surface ozone.

\section{Resolution issue}

In utilizing satellite-based cloud-fraction information, one concern is how to process data in terms of pixel resolution. As already mentioned, the cloud fraction is not a state variable; it is threshold- or retrieval-specific. For example, if we consider an area with 9 pixels with cloud fraction 0.6, fractional averaging of 9 cloud pixels should yield a 0.6 cloud fraction. However, if we first perform cloud masking for each pixel, we may have 9 cloud markings out of 9 pixels, resulting in $100 \%$ cloud fraction. This might not be a critical error on a global scale, but it is a crucial difference for regional or local scales intended for investigating the spatial scale of local ozone production. Since cloud fields are very localized phenomena, this information should be processed as finely as data are available.

To conclude, this study demonstrates that appropriate model of CF is crucial in the modeling of surface ozone chemistry. Further studies are needed in terms of the comparison of modeled- or satellite-based CF with actual surface level photon flux, as well as enhanced parameterization of $\mathrm{CF}$ in the air quality model.

Acknowledgements. The authors like to acknowledge the NOAA National Air Quality Forecast Capability program for its support and thank two anonymous reviewers for their insightful comments.

Edited by: G. A. Folberth

\section{References}

Bergman, J. W. and Salby, M. L.: Diurnal variations of cloud cover and their relationship to climatological conditions, J. Climate, 9, 2802-2820, 1996.

Byun, D. and Schere, K. L.: Review of the Governing Equations, Computational Algorithms, and Other Components of the Models-3 Community Multiscale Air Quality
(CMAQ) Modeling System, Appl. Mech. Rev., 59, 51-77, doi:10.1115/1.2128636, 2006.

Byun, D. W. and Ching, J. K. S.: Science Algorithms of the EPA Models-3 Community Multiscale Air Quality (CMAQ) Modeling System. Washington, DC, USA: US Environmental Protection Agency, Office of Research and Development. 1999.

Castro, T., Madronich, S., Rivale, S., Muhlia, A., and Mar, B.: The influence of aerosols on photochemical smog in Mexico City, Atmos. Environ., 35, 1765-1772, doi:10.1016/S13522310(00)00449-0, 2001.

Chai, T., Kim, H.-C., Lee, P., Tong, D., Pan, L., Tang, Y., Huang, J., McQueen, J., Tsidulko, M., and Stajner, I.: Evaluation of the United States National Air Quality Forecast Capability experimental real-time predictions in 2010 using Air Quality System ozone and $\mathrm{NO}_{2}$ measurements, Geosci. Model Dev., 6, 18311850, doi:10.5194/gmd-6-1831-2013, 2013.

Dickerson, R. R., Kondragunta, S., Stenchikov, G., Civerolo, K. L., Doddridge, B. G., and Holben, B. N.: The Impact of Aerosols on Solar Ultraviolet Radiation and Photochemical Smog, Science, 278, 827-830, doi:10.1126/science.278.5339.827, 1997.

Eastman, R. and Warren, S. G.: A 39-yr survey of cloud changes from land stations worldwide 1971-2009: Long-term trends, relation to aerosols, and expansion of the tropical belt, J. Climate, 26, 1286-1303, 2013.

Eder, B., Kang, D., Mathur, R., Pleim, J., Yu, S., Otte, T., and Pouliot, G.: A performance evaluation of the National Air Quality Forecast Capability for the summer of 2007, Atmos. Environ., 43, 2312-2320, doi:10.1016/j.atmosenv.2009.01.033, 2009.

Fiore, A. M., Dentener, F. J., Wild, O., Cuvelier, C., Schultz, M. G., Hess, P., and Zuber, A.: Multimodel estimates of intercontinental source-receptor relationships for ozone pollution, J. Geophys. Res., 114, 10816, doi:10.1029/2008JD010816, 2009.

Geleyn, J. F., Hense, A., and Preuss, H. J.: A comparison of model generated radiation fields with satellite measurements, Beitr. Phys. Atmos., 55, 253-286, 1982.

He, S. and Carmichael, G. R.: Sensitivity of photolysis rates and ozone production in the troposphere to aerosol properties, J. Geophys. Res., 104, 26307. doi:10.1029/1999JD900789, 1999.

Jacobson, M. Z.: Studying the effects of aerosols on vertical photolysis rate coefficient and temperature profiles over an urban airshed, J. Geophys. Res., 103, 10593, doi:10.1029/98JD00287, 1998.

Kim, H., Ngan, F., Lee, P., and Tong, D.: Development of IDLbased geospatial data processing framework for meteorology and air quality modeling, available at: http://aqrp.ceer.utexas.edu/ projectinfoFY12_135C12-TN25C12-TN2FinalReport.pdf (last access: 21 September 2015), 2013.

Lefer, B. L.: Impact of clouds and aerosols on photolysis frequencies and photochemistry during TRACE-P: 1 . Analysis using radiative transfer and photochemical box models, J. Geophys. Res., 108, 8821, doi:10.1029/2002JD003171, 2003.

Lefer, B. L., Shetter, R. E., Hall, S. R., Crawford, J. H., and Olson, J. R.: Impact of clouds and aerosols on photolysis frequencies and photochemistry during TRACE-P: 1 . Analysis using radiative transfer and photochemical box models, J. Geophys. Res., 108, 8821, doi:10.1029/2002JD003171, 2003.

Liang, J. and Jacobson, M. Z.: Effects of subgrid segregation on ozone production efficiency in a chemical model, Atmos. 
Environ., 34, 2975-2982, doi:10.1016/S1352-2310(99)00520-8, 2000.

Madronich, S.: Photodissociation in the atmosphere: 1. Actinic flux and the effects of ground reflections and clouds, J. Geophys. Res., 92, 9740, doi:10.1029/JD092iD08p09740, 1987.

Martin, R. V., Jacob, D. J., and Yantosca, R. M.: Global and regional decreases in tropospheric oxidants from photochemical effects of aerosols, J. Geophys. Res., 108, 4097, doi:10.1029/2002JD002622, 2003.

Monks, P. S.: Attenuation of spectral actinic flux and photolysis frequencies at the surface through homogenous cloud fields, J. Geophys. Res., 109, D17206, doi:10.1029/2003JD004076, 2004.

Murazaki, K. and Hess, P.: How does climate change contribute to surface ozone change over the United States?, J. Geophys. Res., 111, D05301, doi:10.1029/2005JD005873, 2006.

Nolte, C. G., Gilliland, A. B., Hogrefe, C., and Mickley, L. J.: Linking global to regional models to assess future climate impacts on surface ozone levels in the United States, J. Geophys. Res., 113, D14307, doi:10.1029/2007JD008497, 2008.

Otte, T. L. and Pleim, J. E.: The Meteorology-Chemistry Interface Processor (MCIP) for the CMAQ modeling system: updates through MCIPv3.4.1, Geosci. Model Dev., 3, 243-256, doi:10.5194/gmd-3-243-2010, 2010.

Pour-Biazar, A., McNider, R. T., Roselle, S. J., Suggs, R., Jedlovec, G., Byun, D. W., and Cameron, R.: Correcting photolysis rates on the basis of satellite observed clouds, J. Geophys. Res., 112, D10302, doi:10.1029/2006JD007422, 2007.

Raga, G., Castro, T., and Baumgardner, D.: The impact of megacity pollution on local climate and implications for the regional environment: Mexico City, Atmos. Environ., 35, 1805-1811, doi:10.1016/S1352-2310(00)00275-2, 2001.
Rasmussen, D., Fiore, A., Naik, V., Horowitz, L. W., McGinnis, S. J., and Schultz, M. G.: Surface ozone-temperature relationships in the eastern US: A monthly climatology for evaluating chemistry-climate models, Atmos. Environ., 47, 142-153, doi:10.1016/j.atmosenv.2011.11.021, 2012.

Reidmiller, D. R., Fiore, A. M., Jaffe, D. A., Bergmann, D., Cuvelier, C., Dentener, F. J., Duncan, B. N., Folberth, G., Gauss, M., Gong, S., Hess, P., Jonson, J. E., Keating, T., Lupu, A., Marmer, E., Park, R., Schultz, M. G., Shindell, D. T., Szopa, S., Vivanco, M. G., Wild, O., and Zuber, A.: The influence of foreign vs. North American emissions on surface ozone in the US, Atmos. Chem. Phys., 9, 5027-5042, doi:10.5194/acp-9-5027-2009, 2009.

Schumann, U.: Large-eddy simulation of turbulent diffusion with chemical reactions in the convective boundary layer, Atmos. Environ., 23, 6981, doi:10.1016/0004-6981(89)90056-5, 1989.

Seinfeld, J. H., and Pandis, S. N.: Atmospheric Chemistry and Physics: From Air Pollution to Climate Change, 2nd Ed., 1232 pp., New York, John Wiley and Sons, New York, New York, USA, ISBN: 978-0-471-72018-8, 2006.

Stephens, G. L.: Cloud feedbacks in the climate system: A critical review, J. Climate, 18, 237-273, 2005.

Voulgarakis, A., Wild, O., Savage, N. H., Carver, G. D., and Pyle, J. A.: Clouds, photolysis and regional tropospheric ozone budgets, Atmos. Chem. Phys., 9, 8235-8246, doi:10.5194/acp-9-82352009, 2009.

Wild, O., Zhu, X., and Prather, M.: Fast-J: Accurate simulation of in-and below-cloud photolysis in tropospheric chemical models, J. Atmos. Chem., 37, 245-282, doi:10.1023/A:1006415919030, 2000.

Wyngaard, J. and Brost, R.: Top-down and bottomup diffusion of a scalar in the convective boundary layer, J. Atmos. Sci., 41, 102-112, doi:10.1175/15200469(1984)041<0102:TDABUD>2.0.CO;2, 1984. 